\title{
MicroscopyPioneers
}

\section{Pioneers in Optics: Frits Zernike and John Thomas Queket}

\author{
Michael W. Davidson
}

National High Magnetic Field Laboratory, Florida State University, Tallahassee, FL 32306

davidson@magnet.fsu.edu

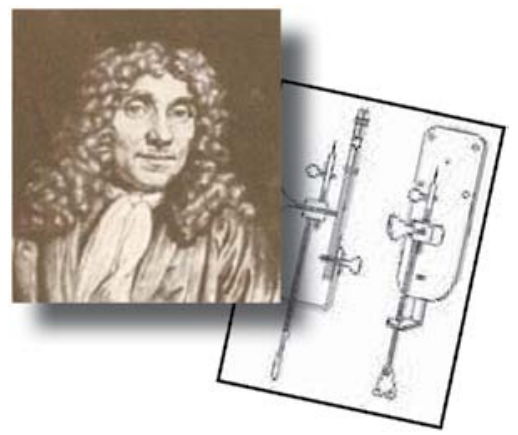

\section{Frits Zernike}

(1888-1966)

Frits Zernike was a Dutch mathematician and physicist who discovered the phase contrast phenomenon and was awarded the Nobel Prize in 1953. Zernike's parents were both teachers who specialized in mathematics, and his siblings also acquired good educations and prestige, with one brother becoming a physicist, a sister who married the well-known painter Jan Mankes, and another sister who rose to become one of Holland's foremost literary writers.

As a young man, Zernike was very interested in physics and chemistry. $\mathrm{He}$ accumulated a variety of spare

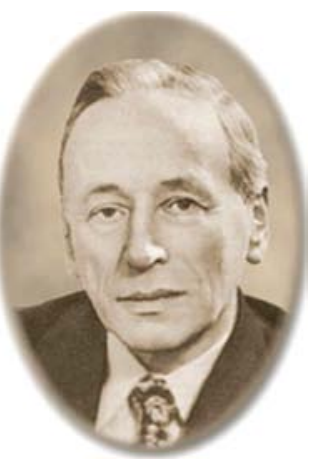
equipment with which he would perform numerous experiments. Zernike was also interested in mathematics, astronomy, and photography and conducted a number of investigations in these areas. He even dabbled in color photography when the field was largely experimental.

Zernike attended the University of Amsterdam in the early 1900s, where he majored in chemistry, with minors in mathematics and physics. While he was an undergraduate, he earned several gold medals for essays on probability and opalescence. Zernike eventually entered the graduate program and received a doctorate in physics in 1915.

He became an assistant to professor Kapteyn at Groningen University in 1913, and he captured his first teaching assignment in mathematical physics at Groningen in 1915. As a researcher, Zernike flourished and studied a wide range of topics, including correlation coefficients for molecules in a liquid, order-disorder theory, and optics.

It was Zernike's studies in optics that ultimately led to his Nobel Prize. He first received evidence of the phase contrast phenomenon in a study of diffraction gratings, when he was able to selectively detect transparent materials with different refractive indices. In 1938, Zernike built a microscope based on phase contrast illumination, but it initially received little attention. At the time, a lack of specimen contrast experienced with common microscopic techniques was one of the major concerns in optical microscopy.

Ironically, it was the German war machine that confiscated his invention and made a series of microscopes, which ultimately demonstrated the true utility of Zernike's technique. After the war, most microscope manufacturers rushed to produce microscopes with this enhanced mode of specimen illumination. Zernike was recognized by the Royal Microscopical Society and was also awarded the prestigious Rumford Metal by the Royal Society of London. His efforts were further rewarded by the Nobel committee with the prize in physics in 1953.

Nobel Prize address. Following are modified excerpts from Zernike's Nobel Prize address, "How I Discovered Phase Contrast," delivered in 1953 in Stockholm, Sweden, and published in the March 11, 1955, issue of Science.

"I did not discover phase contrast while working with microscopes. Rather, it was my involvement with diffraction gratings that led to the breakthrough. Around 1930, our laboratory acquired a sizeable concave grating, and the object's surface appeared striped due to periodic imperfections in the grating lines caused by the ruling machines of the time. Yet, when I focused a telescope on the surface from about six meters away, the stripes disappeared! A succession of experiments and calculations enabled me to explain the phenomenon. In a simpler instance, I found that a telescope with a vertical 2-millimeter slit placed close behind its objective could observe the diffraction pattern of a vertical line-source of light. The diffraction maxima could be observed, but their phases could not be discerned. The phases could be distinguished, however, if the diffraction image was projected onto a coherent background that could serve as a reference. I was familiar with Lord Rayleigh's simple process of making optically sound glass plate etchings using acid and utilized the technique to make what I call phase strips, glass plates with a single groove, one millimeter wide and etched to a depth of half a wavelength. When I placed a phase strip in the spectrum of the faulty grating and inspected it with a telescope, the stripes on the grating surface were clearly visible.

"As a physicist with an interest in optics, it was not difficult for me to move from this subject to the microscope. Recall that Ernst Abbe's theoretical description of the microscope image associates the transparent object under a microscope with a grating. Abbe studied gratings consisting of alternating opaque and transparent strips (amplitude gratings), but I was more concerned with alternating thick and thin strips (phase gratings). Phase gratings generate 


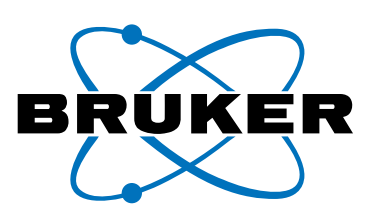

\section{5-in-1 fantasy: Giralope.}

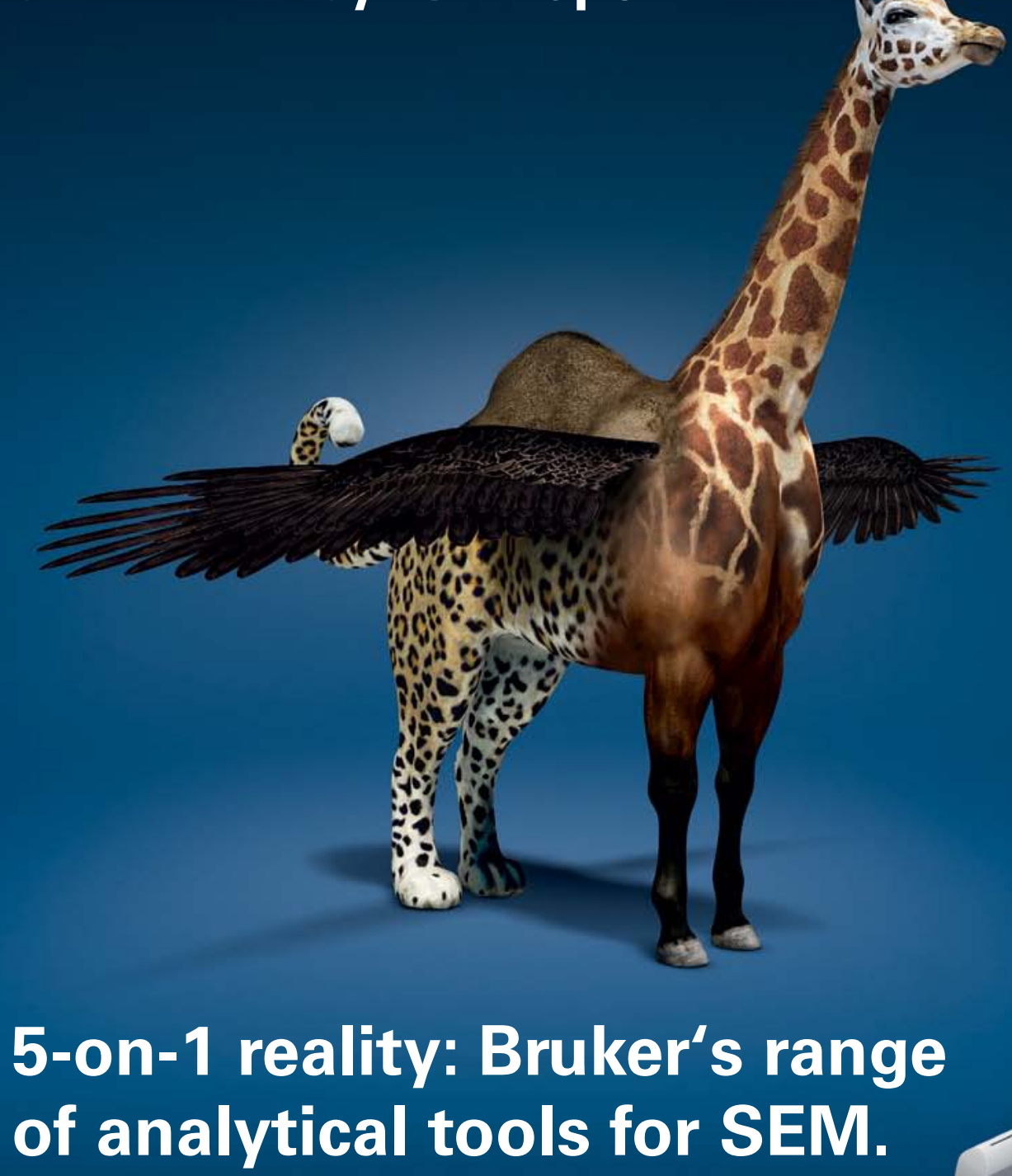

EDS, EBSD, WDS, Micro-XRF and Micro-CT - Bruker is the world's only manufacturer to offer five analysis methods for SEM. Plus, our new ESPRIT 2.0 software not only controls our QUANTAX EDS and QUANTAX EBSD but also, via its functional interface, our innovative new XSense WD spectrometer and XTrace micro-spot X-ray source. And because we know what you expect of us, we are already thinking about our next innovation. Someone has to be first.

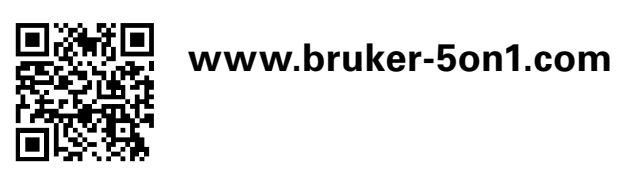


spots of diffraction that demonstrate a phase difference of 90 degrees. For a phase object, when my phase strip is placed in the focal plane of the microscope objective, the direct image of the light source is brought into phase with the diffracted images of a phase object. The result is that the image viewed appears similar to that produced by an amplitude object. The image in the eyepiece of the microscope appears in black and white contrast, as if it were an absorbing object.

"I am impressed by the limitations of the human mind when I look back on these events. We are quick to learnthat is, to emulate what others have already done or thought-but slow to understand, that is, to realize the deeper connections. We are slowest of all, however, in conceiving new connections and in applying old ideas in a new area. In my situation, the truly new point was the fact that the diffraction pattern of the lines of gratings differ in phase from the principal line and that the phases require projection of the diffraction image on a coherent background to be visualized. The full name of the microscopy technique could be something like phase-strip method for observing phase objects in good contrast, but I shortened it to phase contrast."

Presented in Figure 1 are photomicrographs of living tissue culture cells observed in bright-field illumination and phase contrast Original Phase Contrast Photomicrographs of Human Cells to demonstrate the enhanced contrast afforded by the latter technique. These images were taken over fifty

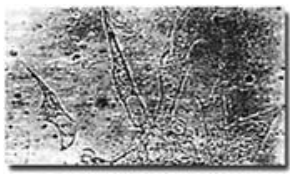

Brightfield

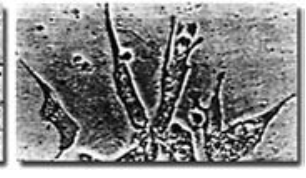

Phase Contrast years ago and represent some of the original work done on phase specimens by Zernike and his colleagues.

Introduction to phase contrast microscopy. Phase contrast microscopy, first described in 1934 by Dutch physicist Frits Zernike, is a contrast-enhancing optical technique that can be used to produce high-contrast images of transparent specimens such as living cells, microorganisms, thin tissue slices, lithographic patterns, and sub-cellular particles (such as nuclei and other organelles). In effect, the phase contrast technique employs an optical mechanism to translate minute variations in phase into corresponding changes in amplitude, which can be visualized as differences in image contrast. One of the major advantages of phase contrast microscopy is that living cells can be examined in their natural state without being killed, fixed, and stained. As a result, the dynamics of ongoing biological processes in live cells can be observed and recorded in high contrast with sharp clarity of minute specimen detail.

\section{John Thomas Quekett \\ (1815-1861)}

Born in England in 1815, John Thomas Quekett was the youngest of four brothers, each with a predilection for natural history. He developed an interest in microscopes early in life. At the age of sixteen he built his own microscope with a roastingjack, parasol, and some fragments of brass. Quekett chose the field of medicine as a career and initially trained with a surgeon in Langport but then went to London as an apprentice to his brother Edwin. He was accepted as a student at the London Hospital Medical College and at Kings College. In 1840 Quekett won a three-year studentship at the Royal College of Surgeons and specialized in human and comparative anatomy.

Although he was to become a surgeon by profession, Quekett continued to harbor a fondness for microscopes that consumed much of his free time. Inspired by Joseph Jackson Lister's 1830 paper on achromatic microscopes, Quekett and his brother Edwin were among the

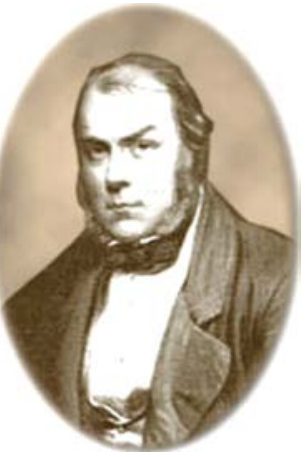
seventeen founding members of the Microscopical Society of London, now known as the Royal Microscopical Society. As the world's first microscopical organization, formation of the group was of great consequence and has resulted in a significant impact on many fields related to microscopy. They began humbly, however, in 1839 at Edwin's house, Number 50 Wellclose Square in London.

A man of many abilities, Quekett developed a distinguished reputation for his histological pursuits. He was rewarded with a professorship in Histology at the Royal College of Surgeons in 1852 and was a popular lecturer. Two volumes on his histology lectures were published. As conservator of the Hunterian Museum at the college, Quekett produced over 16,000 preparations. Badly damaged during the 1941 bombing of London during World War II, only about 6,000 of the original 65,000 specimens survive, 2,500 of which are from Quekett's collection.

Quekett accomplished much during his short lifetime. He was made honorary secretary of the Microscopical Society in 1841, a position he retained for 18 years, until elected its president from 1860 to his death. In 1848, he wrote a Practical Treatise on the Use of the Microscope, an important work leading to rapid growth in the popularity and scientific potential of microscopy. It was also the first work to address specimen preparation techniques for the newly effective compound microscopes. In 1857, he was made a Fellow of the Linnaean Society, and by 1860, a Fellow of the Royal Society. Quekett wrote a letter in 1861 requesting not to be elected president of the Royal Society because of failing health, but the letter was delayed and he later found himself elected. He held office for only a brief period, however, dying only six months later at the age of 46 .

Quekett's efforts in promoting the use of microscopes in modern science became very important as a stepping stone into the world of optics. In 1865 the Quekett Microscopical Club was formed and named in honor of John Quekett for his hard and successful work toward making the microscope a vital scientific research instrument. The group continues as a vital force in the field today, providing amateur microscopists with the opportunity to share the work they love and benefit from each other's experiences. 


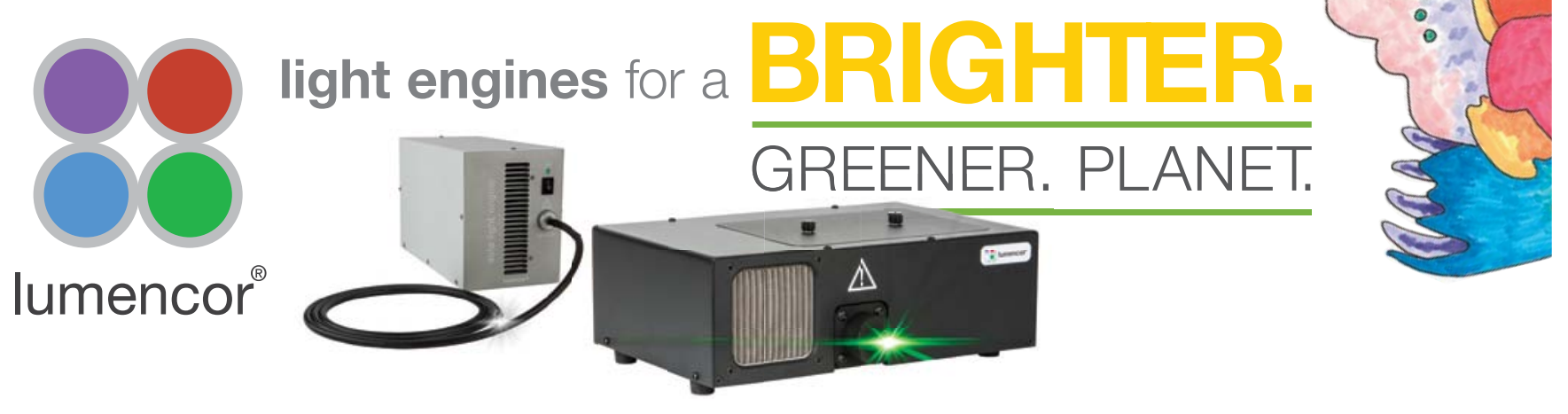

live cell imaging

\section{SPECTRA X LIGHT ENGINE}

Automated control of discrete colored outputs or white light

Six sources throughout the VIS and NIR

Spectral breadth for complete VIS

Automated on/off, color switching and intensity control

Manually replaceable bandpass filters

Microsecond regime switching times fixed cell imaging SOLA SE LIGHT ENGINE

Automated, electronically operable, solid state lamp alternative

Bright, white light

Spectral breadth for complete VIS

Fast on/off and intensity control

LUMENCOR, INC

T 503.213.4269 • info@lumencor.com mercury free, solid state lamp SOLA SM LIGHT ENGINE

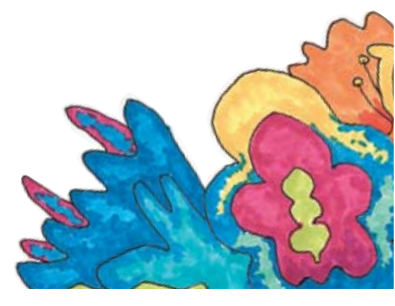

\section{Expand your Knowledge of Microscopy with} MSA Membership!

Whether your primary focus is in optical, electron or scanning probe microscopy, the biological or the physical sciences, MSA takes your knowledge to the next level!

Members Receive:

- A personal subscription to MSA's official journal, Microscopy and Microanalysis, and MSA's popular bi-monthly magazine, Microscopy Today.

- Peer Networking through the Society's Focused Interest Groups and Local Affiliated Societies.

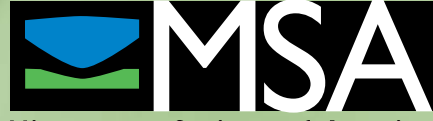

Microscopy Society of America
- Plus discounts on books, journals and other educational materials.

- MSA Awards Programs, Scholarships, Speaker Opportunities, and much more! 